\title{
HORIZONTAL FLUX OF SUSPENDED PARTICLES SAMPLING BY BIG SPRING NUMBER EIGHT (BSNE) SAMPLER IN LAKE URMIA AREA
}

\author{
ZABIHI, F. ${ }^{1}$ - ESFANDIARI, M. ${ }^{1}$ - DALALIAN, M. R. ${ }^{2 *}-$ MOEINI, A. ${ }^{1}$ \\ ${ }^{I}$ Department of Soil, Science and Research Branch, Islamic Azad University \\ Tehran, Iran \\ (phone: +98-914-104-5508; +98-912-947-6853; fax: +98-21-2240-3348) \\ ${ }^{2}$ Department of Soil Science, Tabriz Branch, Islamic Azad University \\ Tabriz, Iran \\ *Corresponding author \\ e-mail:mdalalian@iaut.ac.ir; phone: +98-912-520-2818 \\ (Received $14^{\text {th }}$ Aug 2017; accepted $15^{\text {th }}$ Jan 2018)
}

\begin{abstract}
Lake Urmia has become one of the key dust sources in northwestern of Iran due to a sharp drop in its water level that caused an increasing dried land around the lake area. There has not been any studied concerning of how much dust is emitted and transported in this area. The aim of this research study was to measure the amount of dust suspended particles flux in the lake area. To implement this objective, 56 aeolian dust samplers were mounted at $0.15,0.5,1$ and $2 \mathrm{~m}$ heights in 14 different poles and the suspended particles flux was measured during one year period. The data showed that the flux in March, June, and October accounted for 53\% of the annual total. The suspended particles flux decrease rapidly with increasing height of soil surface. The obtained data showed that the suspended particles flux is strongly correlated with the amount of monthly precipitation and mean wind velocity but there was no significant relationship between monthly suspended particles flux and speed of the strongest wind.The result also showed that the wind direction did not influence flux. Different heights of the soil surface, sampling times and sampling sites had significant $(\mathrm{P} \leq 0.01)$ effects on flux.
\end{abstract}

Keywords: dust center, height of soil surface, sampling site, sampling time, wind erosion, wind speed

\section{Introduction}

According to FAO report, approximately 430 million ha of drylands, which comprise $40 \%$ of earth's surface are susceptible to wind erosion. Many studies have estimated the amount of global wind erosion and dust transport. However, because the wind not only mobilizes dust but also transport coarser soil particles (sand), therefore the estimation of the total amount of wind erosion especially amount of dust is uncertain. The rate of global dust emission is reported in a range of $5 \times 10^{11}$ to $33.2 \times 10^{11} \mathrm{~kg} \mathrm{yr}^{-1}$. The studies of dust sources that were concluded by global-scale high-resolution satellite imagery, showed that natural dust sources do account for about $75 \%$ of dust emission and the remaining $25 \%$ of emission were attributed to anthropogenic sources. The fraction of dust sources is highly variable (FAO, 2015).

The Lake Urmia which is located in northwestern of Iran is one of the main sources of aeolian dust in Iran. This lake has shown a sharp drop in water level due to decreasing in rainfall precipitation and excessive water intake, especially for agricultural consumption. The human factors such as the construction of numerous dams on the rivers that lead to the lake and the drill of multiple unauthorized wells are considered for water decline. According to the reports, during the last 20 years (1995 to 2015), the water level of the Lake Urmia has fallen by 8 meters (Tajrishi, 2016). The 
area of Lake Urmia is $5822 \mathrm{~km}^{2}$. According to official reports, more than $80 \%$ of it was dried in 2013. This means that about $4657 \mathrm{~km}^{2}$ area is converted into drylands (Asghai Zamani, 2013). Unfortunately, the trend has been continued and this area is highly exposed to wind erosion and susceptible to generate dust particles with a diameter less than $0.1 \mathrm{~mm}$. Therefore, the Lake Urmia is considered to be a key source area for dust storms in N.W. of Iran.

The strong dust transport that occurs during dust storms often creates a serious hazard for human (Dong et al., 2010). If the dust transportation continues and after passing some distance and settles into the ground surfaces, the salinity of these particles may cause to increase the salinity of agricultural lands in the region. The results of the chemical soil test in the area showed that the salinity of the investigated soil was very high $\left(\mathrm{EC}=143.1\right.$ Ds. $\mathrm{m}^{-1}$ and SAR $\left.=80.5\right)$.

On the other hand, drying of the Lake Urmia caused the reflection of solar radiation to increase. The Albedo coefficient of drylands around the lake was 5.2 times more from 2007 to 2013. The diseases that caused by frequent exposure to ultraviolet radiation include cancer, eye injuries (black eyes, cataracts, burns, blindness, and luminosity) and dermatological injuries (Tajrishi, 2016). Also, it has been reported that if the amount of suspended particles in the air exceeds the limit of $\left(15 \times 10-{ }^{8} \mathrm{~kg} \cdot \mathrm{m}^{-3}\right)$, it will cause respiratory illnesses. These factors threaten the lives of more than 7 million people in the region.

Even though, many types of research have designated to transform and provide guidance to water level restoration, but there is no information on the amount of suspended particle caused by wind erosion in the drylands area of the Lake Urmia. Government officials especially Urmia Lake Restoration Program just paying attention to restore the water level to this lake.

In studies of aeolian dust, the most important parameter is the amount of dust transported in the air (i.e., the horizontal dust flux) (Dong et al., 2010). Hence in order to provide suggestions and solutions for dealing with wind erosion especially suspended particles in the air, we need to know the amount of suspended particle flux and their transportation mechanism of how it is changing at different heights of soil surface at different sampling times and different sampling distance sites.

To support such goals, we need to accurately install the instrument to trap the suspended particles. The wind tunnels designed to study wind erosion limit the maximum height of studied particles (normally the height of particles being tested should not exceed $1 / 4$ to $1 / 3$ the height of the tunnel). Thus, to translate wind tunnel soil losses to equivalent losses from a field is difficult. Also, wind tunnels do not study erosion events for long-term (Fryrear et al., 1988).

Using the samplers to study the suspended particles has started since 1957 and has been changed a lot to increase the efficiency of samplers. The last and most advanced sampler for suspended particles gathering is BSNE (Big Spring Number Eight) sampler that was made by Donald Fryrear in Big Spring-Texas for the first time in 1986. More important properties of this sampler include (a) its ability to orientate into erosive winds; (b) the possibility to collect samples from different heights at the same location; (c) the least need to servicing and controlling for long collection periods; (d) its ability to earn data of vertical and horizontal distribution; (e) its construction is simple and it is durable (Fryrear, 1986). Studies that compare this sampler with other samplers have shown that this sampler is the most efficient and recommended sampler for field 
measurements (Goossens and Offer, 2000; Shannak et al., 2014; Goossens and Buck, 2012; Dong et al., 2010).

The objective of this research study was to investigate and presents results for the amount of horizontal suspended particles flux and its variation with different heights, sampling time and sampling site based on continuous sample collection and detail observation from March 2016 until February 2017 for assessing wind erosion in the studied area.

\section{Materials and methods}

\section{Location}

In this study, one of the dust centers that located in the southeastern zone of Lake Urmia was selected (Fig. 1 C). This area was exposed to wind erosion and it was a suitable place to study wind erosion and the flux of suspended particles. Lack of insignificance of earth's slope gradient, shortage of plant cover and having high wind speed and low rainfall (the average 11 years of meteorological information of a studied region in duration from 2000 to 2011 that were obtained from Tabriz weather station has been shown in Table 1) are parameters used to select location sites.

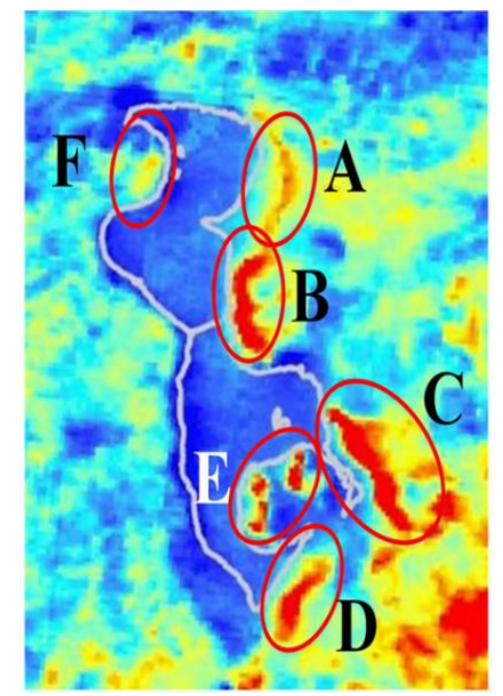

Figure 1. Plan of dust centers around Lake Urmia (recognized by BTD methods - one of the recognition methods based on Brightness temperature difference) (Tajrishi, 2016)

Table 1. The average 11 years of meteorological information of studied zone (from 2000 to 2011)

\begin{tabular}{c|c|c|c|c|c|c|c|c|c|c|c|c}
\hline Months & Jan. & Feb. & Mar. & Apr. & May & Jun. & Jul. & Aug. & Sep. & Oct. & Nov. & Dec. \\
\hline $\begin{array}{c}\text { Mean wind } \\
\text { velocity }\left(\mathrm{m} . \mathrm{s}^{-1}\right)\end{array}$ & 0.99 & 1.89 & 5.17 & 2.7 & 2.44 & 5.03 & 5.11 & 3.96 & 1.54 & 1.81 & 1.52 & 0.95 \\
$\begin{array}{c}\text { Speed of strongest } \\
\text { wind }\left(\mathrm{m} . \mathrm{s}^{-1}\right)\end{array}$ & 30 & 30 & 45 & 25 & 30 & 38 & 28 & 45 & 80 & 40 & 30 & 25 \\
$\begin{array}{c}\text { Total amount of } \\
\text { rainfall }(\mathrm{mm})\end{array}$ & 24.21 & 20.95 & 3.9 & 53.41 & 27.29 & 1.86 & 2.41 & 2.19 & 27.06 & 12 & 20.55 & 23.9 \\
\hline
\end{tabular}


Geographical location of the studied region was $45^{\circ} 51^{\prime} 0.771^{\prime \prime}$ eastern longitude and $37^{\circ} 47^{\prime} 0.675^{\prime \prime}$ northern latitude with semi-arid and cold climate. This zone was located at $30 \mathrm{~km}$ distance from the Tabriz-Azarshahr road and western south of EastAzarbayjan province- Khasselou village. Topsoil samples that were taken from the zoned area had $28 \%$ sand, $40 \%$ silt, and $32 \%$ clay. The bulk density of soil was $1.34 \mathrm{gr} . \mathrm{cm}^{-3}$ and soil texture was clay loam (Table 2).

Table 2. Results of chemical and physical analysis of the initial soil

\begin{tabular}{c|c|c|c|c|c|c|c|c|c|c}
\hline $\begin{array}{c}\text { Depth } \\
(\mathbf{c m})\end{array}$ & Sand\% & Silt\% & Clay\% & $\begin{array}{c}\text { Soil } \\
\text { texture }\end{array}$ & $\begin{array}{c}\mathbf{\rho b} \\
\left(\mathbf{g r . c m}^{-3}\right)\end{array}$ & $\begin{array}{c}\mathbf{E C e} \\
\left(\mathbf{d S . m}^{-1}\right)\end{array}$ & $\mathbf{p H}$ & \% T.N.V & \%OC & SAR \\
\hline $0-10$ & 28 & 40 & 32 & C-L & 1.34 & 143.1 & 7.84 & 16.25 & 0.45 & 80.5 \\
$10-20$ & 25 & 42 & 33 & C-L & 1.35 & 142.1 & 7.95 & 16.21 & 0.4 & 79.5 \\
$20-30$ & 20 & 45 & 35 & C-L & 1.32 & 140 & 8 & 16.22 & 0.39 & 79 \\
\hline
\end{tabular}

\section{Field instrument}

In this study, the modified BSNE samplers with opening $20 \mathrm{~mm}$ wide and $50 \mathrm{~mm}$ height were used. The 18 mesh stainless screen in the opening of sampler for dust entering and the 120 mesh stainless steel screen on the top of the sampler was used which allowed the air to exit while the airborne material remained in the sampler tray. 4 samplers were installed on the same mounting pole (a $1 / 2$ " steel pipe with an outside diameter of $1.8 \mathrm{~cm}$ ) at $0.15,0.5,1$ and $2 \mathrm{~m}$ heights of the soil surface (Fryrear et al., 1991). An $18 \times 20 \mathrm{~cm}$ sheet provided as sampler tail that accompanied by a rubber retainer in lower of each sampler that allowed to rotate and orient according to wind direction (Figs. 2 and 3). 14 poles were installed in a circular pattern (Fig. 4) inside 3.2 ha area. This pattern permitted field erosion data collection regardless of the wind direction and provided a range of field lengths with a minimum number of sampler locations (Fryrear et al., 1991).

\section{Samples gathering and analytical methods}

Totally, 56 samplers were installed in the above-mentioned pattern. After 30 days of installing, the tray of each sampler was evacuated and gathered particles were dried at $105^{\circ} \mathrm{C}$ and transported to the laboratory for physical testing. This gathering was continued monthly in 12 interval periods (from March 2016 until February 2017).

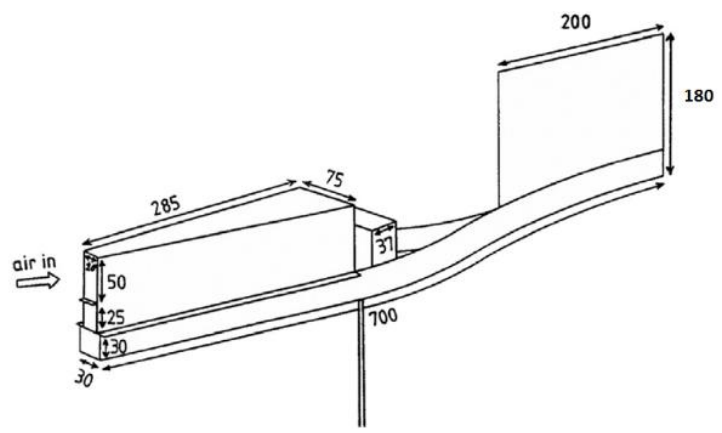

Figure 2. BSNE sampler-(all dimensions are in $\mathrm{mm}$ ) 

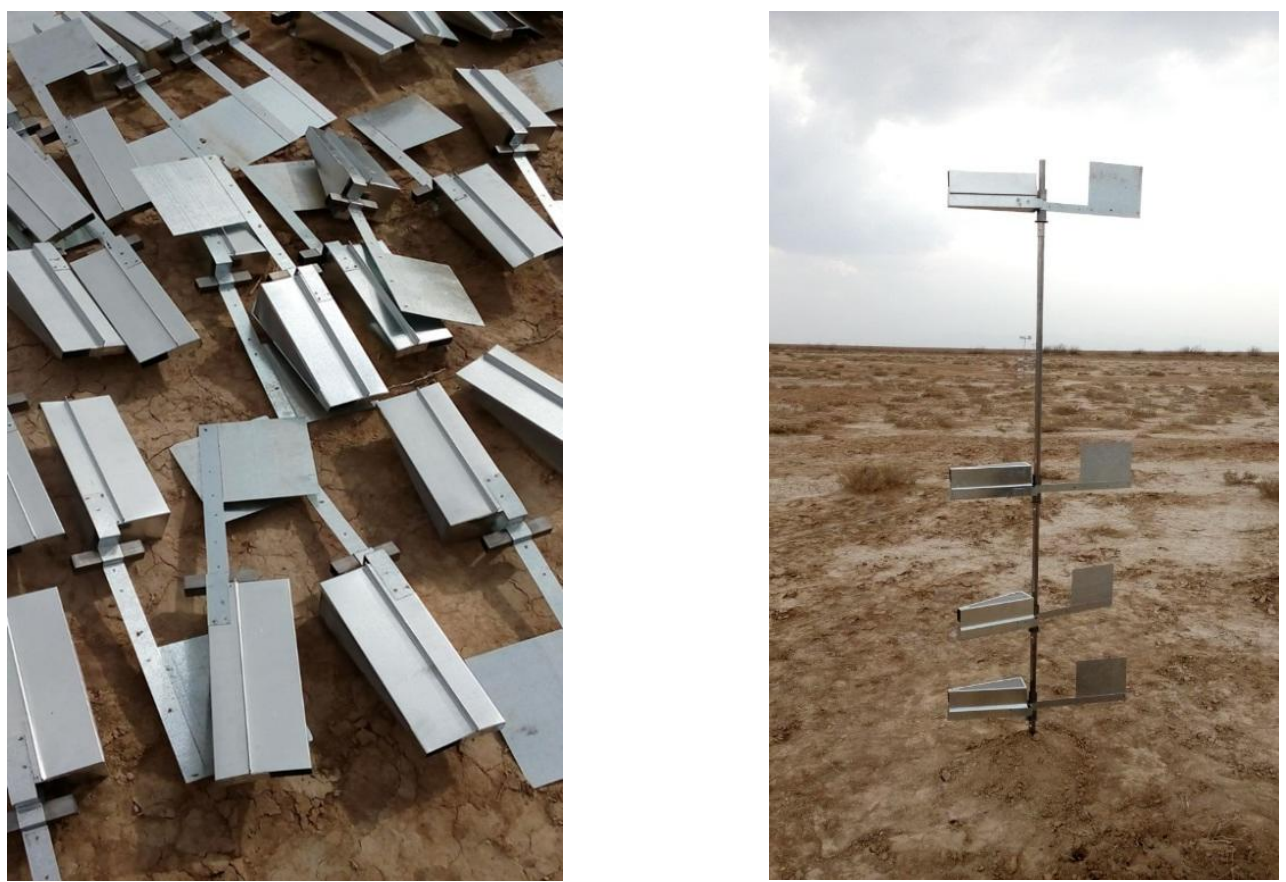

Figure 3. Samplers that were made and installed

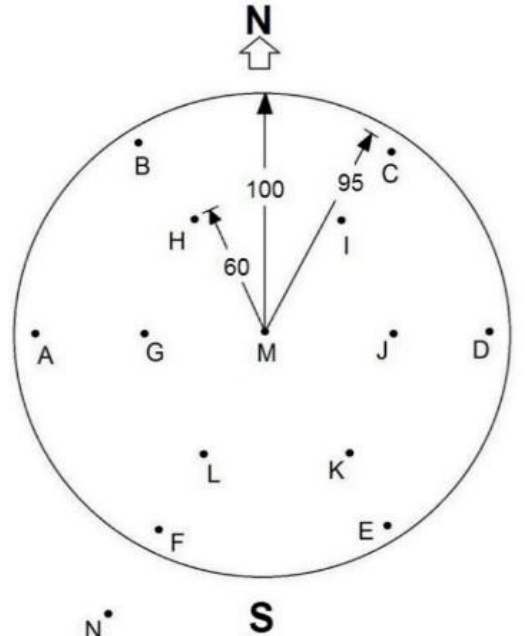

Figure 4. The installation pattern of 14 poles

To determine the horizontal flux of suspension particles, sample weight of suspended gathered particles calculated via particle size distribution curve (particles were sieved via series with $18,30,60,100,200,270$ and 400 meshes that corresponds to 1, 0.595, $0.25,0.149,0.074,0.053$ and $0.037 \mathrm{~mm}$ in diameters respectively). Horizontal flux was calculated by the formula in Equation 1 (Wang et al., 2004):

$$
F=\frac{W}{S . T}
$$


where $\mathrm{F}=$ horizontal flux of suspension particles $\left(\mathrm{kg} \cdot \mathrm{m}^{-2} \cdot \mathrm{mon}^{-1}\right), \mathrm{W}=$ weight of suspension particles sampled by sampler $(\mathrm{kg}), \mathrm{S}=$ area of sampler opening $\left(\mathrm{m}^{2}\right)$ and $\mathrm{T}=$ time (mon).

According to Goossens and Buck (2012) findings, there was no relation between the efficiency of BSNE sampler and wind velocity. Therefore the sampling efficiency of the sampler was supposed to be constant of wind velocity and they used Equation 2 for efficiency estimating of suspended particles.

$$
y=-0.0047 x^{2}+1.2145 x+6.1302
$$

This equation showed that there was a strong relationship between the sampling efficiency ( $\mathrm{y}$ in percent) with the particles diameter ( $\mathrm{x}$ in micron); $\left(\mathrm{r}^{2}=0.9969\right)$.

This equation was constant for particles larger than $10^{-4} \mathrm{~m}(0.1 \mathrm{~mm})$ (the upper boundary of suspended particles). In this study the equation 2 for efficiency estimating of made samplers was used.

To study the effect of sampling time (during the research period from March 2016 until February 2017) and height of soil surfaces $(0.15,0.5,1$ and $2 \mathrm{~m})$ on suspended particles flux, the data of calculated flux in different times and different heights of soil surface were analyzed. Factorial experiment on the basis of completely randomized design with 14 replication was carried out. Also, to study the effect of sampling time and sampler's distance from each other (14 sites of installation of the poles) on suspended particles flux, the data of calculated flux in different times and different sites were analyzed. Factorial experiment on the basis of completely randomized design with 4 replication was carried out. Comparison of means by Duncan multiple range test at $1 \%$ probability level was carried out. Before data analyzing, the normality test of variables was carried out. Data analysis was done using SPSS-16 software and the graphs and tables were drew by Excel software.

The data of meteorological information of studied zone during research period were obtained from Tabriz weather station (Table 3). As seen in the table the range of mean wind velocity varied from 3.3 to $8.1 \mathrm{~m} . \mathrm{s}^{-1}$. The maximum speed of strongest wind was $20 \mathrm{~m} . \mathrm{s}^{-1}$ in November. The minimum horizontal vision varied from $0.02 \mathrm{~km}$ in January 2017 to $7 \mathrm{~km}$ in August 2016. The highest rainfall was $68.6 \mathrm{~mm}$ in April 2017, and the lowest was $0 \mathrm{~mm}$ in August 2016. This report showed that the highest and lowest amount of rainfall in the months exactly corresponds to the average 11 years of meteorological data gathering (Table 2).

\section{Results and discussion}

\section{Variation in horizontal flux with height}

The variation of horizontal suspended particle's flux with a height of soil surface (the flux profile) is expressed by a power law (Eq. 3).

$$
f(z)=a z^{b}
$$

where $\mathrm{f}(\mathrm{z})$ is the horizontal suspended particle's flux $\left(\mathrm{kg} \cdot \mathrm{m}^{-2} \cdot \mathrm{mon}^{-1}\right)$ at height $\mathrm{z}(\mathrm{m})$ and $\mathrm{a}, \mathrm{b}$ are regression coefficients. 
Table 3. Meteorological information of studied zone during research period (March 2016February 2017)

\begin{tabular}{|c|c|c|c|c|c|c|c|c|c|c|c|c|c|c|}
\hline \multirow[t]{2}{*}{ Date } & \multirow{2}{*}{$\begin{array}{c}\text { Minimum } \\
\text { surface } \\
\text { temperature } \\
\left({ }^{\circ} \mathbf{C}\right)\end{array}$} & \multicolumn{3}{|c|}{$\begin{array}{c}\text { Air temperature } \\
\left({ }^{\circ} \mathrm{C}\right)\end{array}$} & \multicolumn{3}{|c|}{$\begin{array}{c}\text { Relative air } \\
\text { moisture (\%) }\end{array}$} & \multirow{2}{*}{$\begin{array}{c}\text { Mean } \\
\text { wind } \\
\text { velocity } \\
\left(\mathbf{m . s}^{-1}\right)\end{array}$} & \multirow{2}{*}{$\begin{array}{c}\text { Speed of } \\
\text { strongest } \\
\text { wind } \\
\left(\mathrm{m}^{-1} \mathbf{s}^{-1}\right)\end{array}$} & \multirow{2}{*}{$\begin{array}{c}\text { Direction } \\
\text { of } \\
\text { strongest } \\
\text { wind }\end{array}$} & \multirow{2}{*}{ 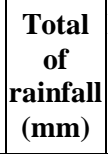 } & \multirow{2}{*}{$\begin{array}{c}\text { Maximum } \\
\text { of daily } \\
\text { rainfall } \\
(\mathbf{m m})\end{array}$} & \multicolumn{2}{|c|}{$\begin{array}{c}\text { Horizontal } \\
\text { vision } \\
(\mathbf{k m})\end{array}$} \\
\hline & & Min & Max & Mean & Min & Max & Mean & & & & & & Min & Max \\
\hline Mar-16 & -1.2 & -3.2 & 19.2 & 7.9 & 21 & 97 & 57.5 & 8.7 & 15 & 360 & 1.5 & 10 & 2.5 & 25 \\
\hline Apr-16 & 0.1 & -3.8 & 20.4 & 9.1 & 20 & 98 & 62.5 & 4.4 & 19 & 330 & 46.6 & 23.3 & 0.3 & 30 \\
\hline May-16 & 5.1 & 2.4 & 28.6 & 16.2 & 13 & 96 & 54 & 6.8 & 16 & 340 & 26.1 & 18.7 & 2.3 & 30 \\
\hline Jun-16 & 9.21 & 10 & 32.2 & 20.5 & 11 & 94 & 44.5 & 7.5 & 19 & 210 & 1.1 & 12.8 & 2 & 25 \\
\hline Jul-16 & 16.1 & 15.6 & 38.4 & 26.2 & 8 & 84 & 38.8 & 5.6 & 16 & 070 & 3.3 & 2.5 & 5 & 25 \\
\hline Aug-16 & 18.5 & 17 & 39.4 & 28.6 & 7 & 68 & 31.8 & 6.1 & 13 & 060 & 1.8 & - & 7 & 20 \\
\hline Sep-16 & 12.6 & 11 & 37.4 & 24.5 & 8 & 80 & 34.8 & 7.1 & 17 & 350 & 1.7 & 4.1 & 4 & 27 \\
\hline Oct-16 & 3.7 & 1.8 & 28.8 & 16 & 9 & 90 & 39.9 & 7.7 & 18 & 350 & 1.3 & 0.7 & 2.5 & 35 \\
\hline Nov-16 & -0.4 & -4.2 & 20.8 & 8.6 & 21 & 97 & 61.8 & 5.4 & 10 & 230 & 26.4 & 8.4 & 0.5 & 30 \\
\hline Dec-16 & -8.9 & -14.4 & 11.6 & -0.6 & 17 & 96 & 61.2 & 4.8 & 6 & 350 & 23 & 10.5 & 0.15 & 30 \\
\hline Jan-17 & -13.8 & -18 & 5.4 & -5.5 & 50 & 97 & 76.3 & 3.3 & 6 & 300 & 24.6 & 8.1 & 0.02 & 12 \\
\hline Feb-17 & -9 & -16 & 6.7 & -3.2 & 38 & 95 & 67.8 & 4.3 & 12 & 150 & 22.4 & 2.1 & 0.3 & 30 \\
\hline
\end{tabular}

Figure 5 shows the variation in horizontal flux collected by the BSNE sampler as a function of the height of soil surface for every month during the duration of the research period. In all cases, the horizontal suspended particle's flux decreases with increasing height of soil surface.

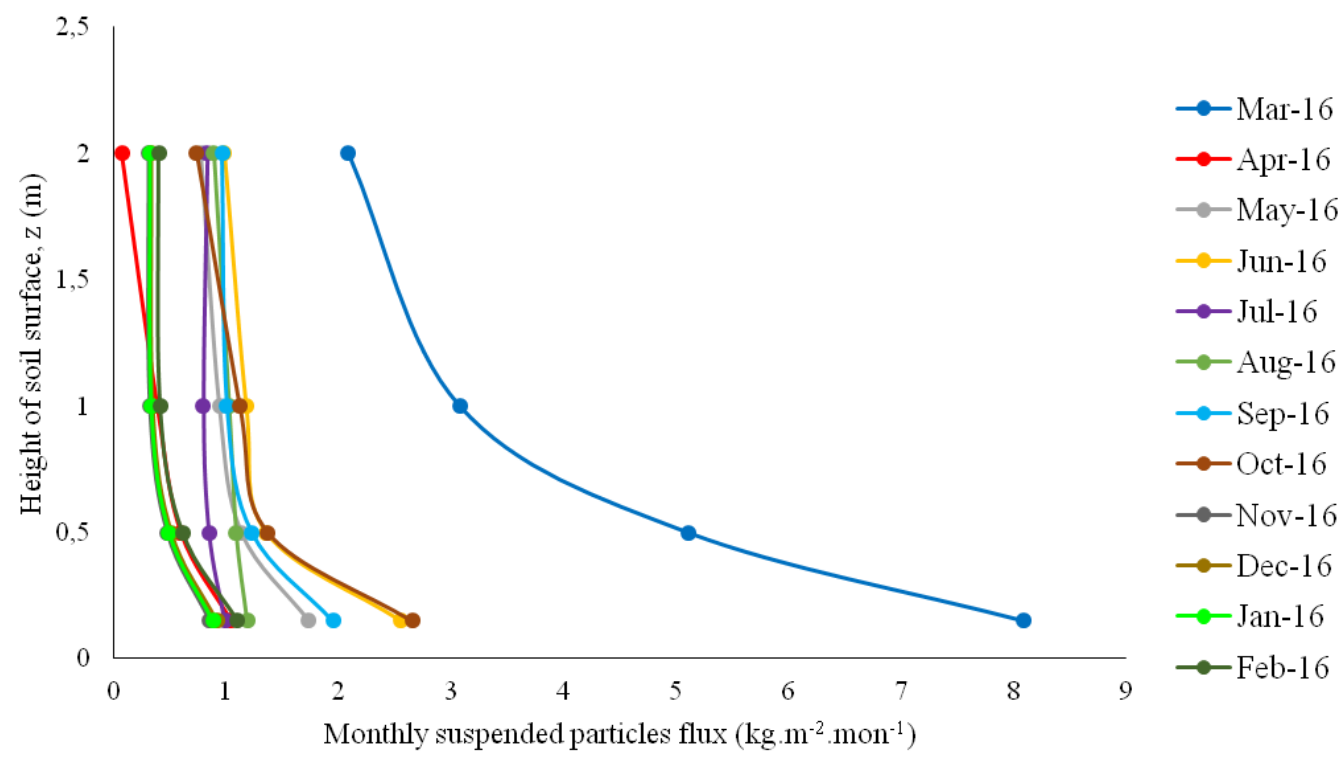

Figure 5. Vertical profile of suspended particles flux (from Mar. 2016 until Feb. 2017)

Previous researchers had shown the variation in Aeolian sediment flux as a function of height that were focused on saltation. The Aeolian saltation flux decayed with height exponentially, but Dong and et al. (2010) and Fryrear and Saleh (1993) based on another author's reports explained that power function could better describe this variation. They noticed that the flux of suspended sediments decayed relatively gently with height compared with the saltation flux. Fryrear (1987) and Zobeck and Fryrear 
(1986) used a power function for Aeolian sediment flux at height as low as $0.15 \mathrm{~m}$. Vories and Fryrear (1988) recommended only applying a power function to the height of $0.5 \mathrm{~m}$ and above because more of the particles below $0.5 \mathrm{~m}$ were saltation. Dong and et al. (2010) concluded that the Aeolian sediment flux at height below $5 \mathrm{~m}$ decays more rapidly than above $5 \mathrm{~m}$ with increasing height of soil surface, also the flux data above 5 $\mathrm{m}$ showed wider scattering than those at lower heights, but the overall variation with height can nonetheless be reasonably well explained using a power function.

By summing up the monthly suspended particles flux for each height reveals that the variation of the annual flux as a function of height can also be explained well by using a power function $\left(\mathrm{r}^{2}=0.9981\right)($ Eq. 4 and Fig. 6).

$$
F(z)=447.5 z^{-2.523}
$$

where $F(z)$ is the annual sediment flux $\left(\mathrm{kg} \cdot \mathrm{m}^{-2} \cdot \mathrm{mon}^{-1}\right)$ at height $\mathrm{z}(\mathrm{m})$.

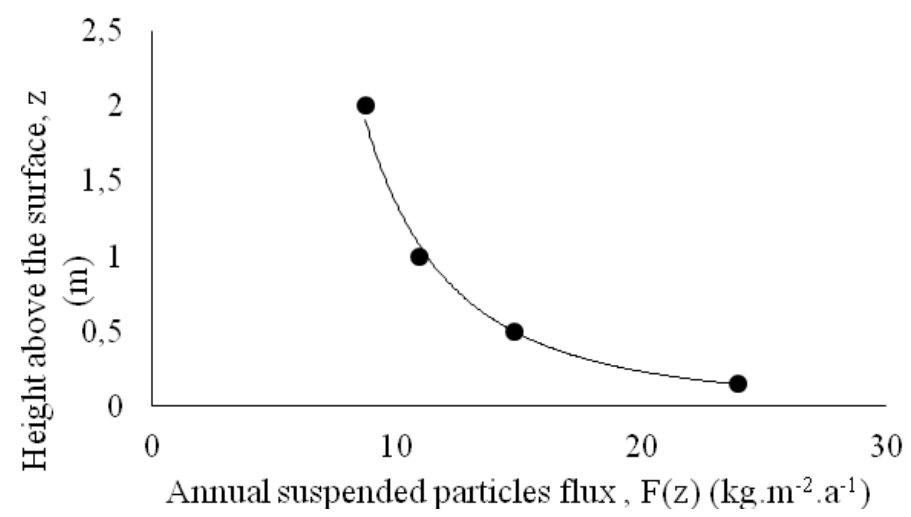

Figure 6. Variation in annual suspended particle's flux), $F(z)$, as a function of height (z)

Results of the regression analysis between the fluxes of suspended particles as a function of the height of soil surface had been shown in Table 4.

Table 4. Results of the regression analysis between the flux of suspended particles as a function of height

\begin{tabular}{c|c|c|c}
\hline Month & $\mathbf{a}$ & $\mathbf{b}$ & $\mathbf{r}^{\mathbf{2}}$ \\
\hline Mar. 2016 & 8.2427 & -1.852 & 0.9812 \\
Apr. 2016 & 0.2555 & -0.887 & 0.8282 \\
May 2016 & 0.8287 & -3.207 & 0.9952 \\
June 2016 & 1.5311 & -2.595 & 0.9535 \\
July 2016 & 0.137 & -10.15 & 0.7465 \\
Aug. 2016 & 0.8835 & -8.737 & 0.9241 \\
Sept. 2016 & 1.2509 & -3.317 & 0.94 \\
Oct. 2016 & 1.0936 & -2.055 & 0.989 \\
Nov. 2016 & 0.099 & -2.288 & 0.9475 \\
Dec. 2016 & 0.1177 & -2.288 & 0.9475 \\
Jan. 2017 & 0.1072 & -2.288 & 0.9475 \\
Feb. 2017 & 0.1786 & -2.288 & 0.9475 \\
\hline
\end{tabular}


The cumulative percentage of the annual suspended particles flux as a function of the height of soil surface (Fig. 7) derived from Equation 4 shows that $80 \%$ of flux was transported below $80 \mathrm{~cm}$ and $90 \%$ below $120 \mathrm{~cm}$ of the surface. This suggests that the majority of suspended particles flux moves below $1 \mathrm{~m}$ height of soil surface and will settle back to the ground in a short distance and that only a small fraction will be transported over long distances. These results are according to Dong et al. (2010).

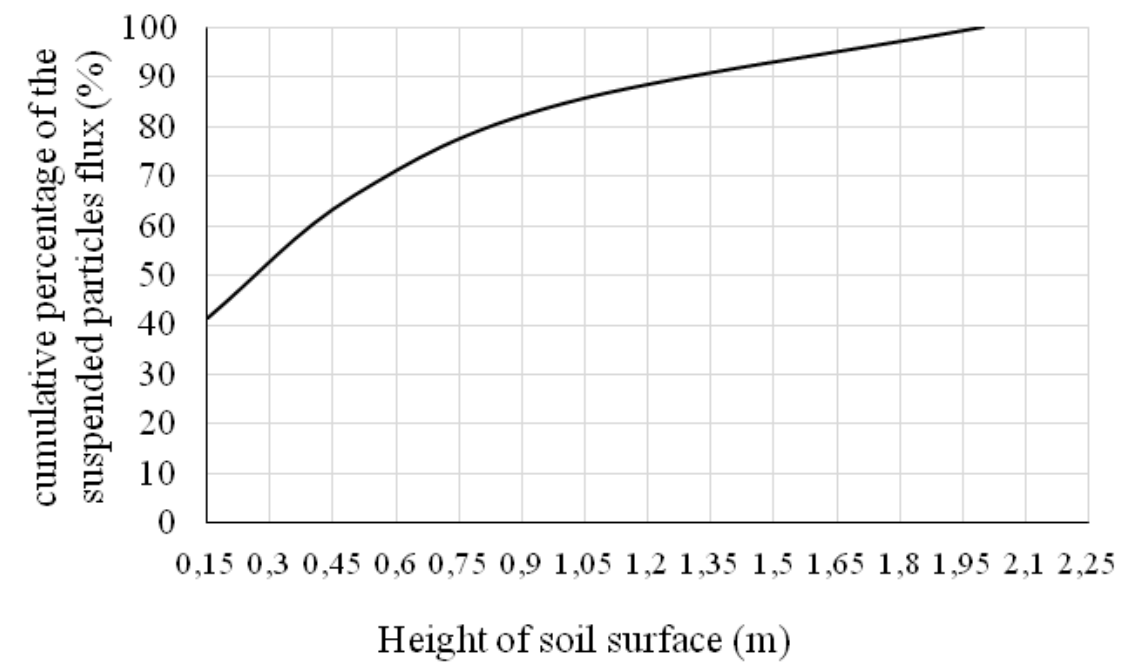

Figure 7. Plot of cumulative percentage of the annual flux of suspended particles as a function of height

\section{Variation in monthly suspended particles flux}

If the variation in suspended particles flux with height for a given month can be established, the monthly total suspended particles flux can be calculated as follows (Eq. 5):

$$
F_{i}=\int_{0}^{\infty} f_{i}(z) d z
$$

where $F_{i}$ is the total suspended particles flux passing through a unit width in a month $\mathrm{I}$ and $f_{i}(z)$ is the function for month $\mathrm{i}$. In theory, $f_{i}(z)$ can be considered as equivalent to the regression function in Equation 3 that we obtained earlier. The annual suspended particles flux fitted Equation 4 with smaller errors. Dong et al. (2010) concluded that the monthly total suspended particles flux can be estimated by Equation 6 .

$$
F_{i}=\frac{F_{i o b}}{F_{o b}} \int_{0}^{\infty} F(z) d z
$$

where $F_{\text {iob }}$ is the observes total suspended particles flux in the month I that is obtained by summing the monthly suspended particles flux collected at all 4 heights, and $F_{o b}$ is the observed annual total suspended particles flux obtained by summing the annual 
suspended particles flux at all 4 heights. $\mathrm{F}(\mathrm{z})$ is the function of the variation in annual suspended particles with height (Eq. 4). Hence Equation 7 can be used to estimate the monthly total suspended particles flux.

$$
F_{i} \approx \frac{F_{i o b}}{F_{o b}} \int_{0}^{z} F(z) d z=\frac{F_{i o b}}{F_{o b}} \int_{0}^{\infty} 447.5 z^{-2.523} d z=-\frac{F_{i o b}}{F_{o b}} 293.83 z^{-1.523}
$$

Figure 8 shows the relationship between the total monthly suspended particles flux and the main meteorological parameters at the study site during research period (from Mar. 2016 until Feb. 2017). Correlation coefficients between monthly suspended particles flux (F) and monthly precipitation (P), speed of the strongest wind (SW) and monthly mean wind velocity (MW) showed that the monthly suspended particles flux is strongly correlated with the monthly precipitation and monthly mean wind velocity, but there was no significant relationship between monthly suspended particles flux and speed of the strongest wind (Table 5). This can be explained by the fact that when the monthly precipitation is low, the soil surface is arid and prone to the emission of suspended particles into the air.

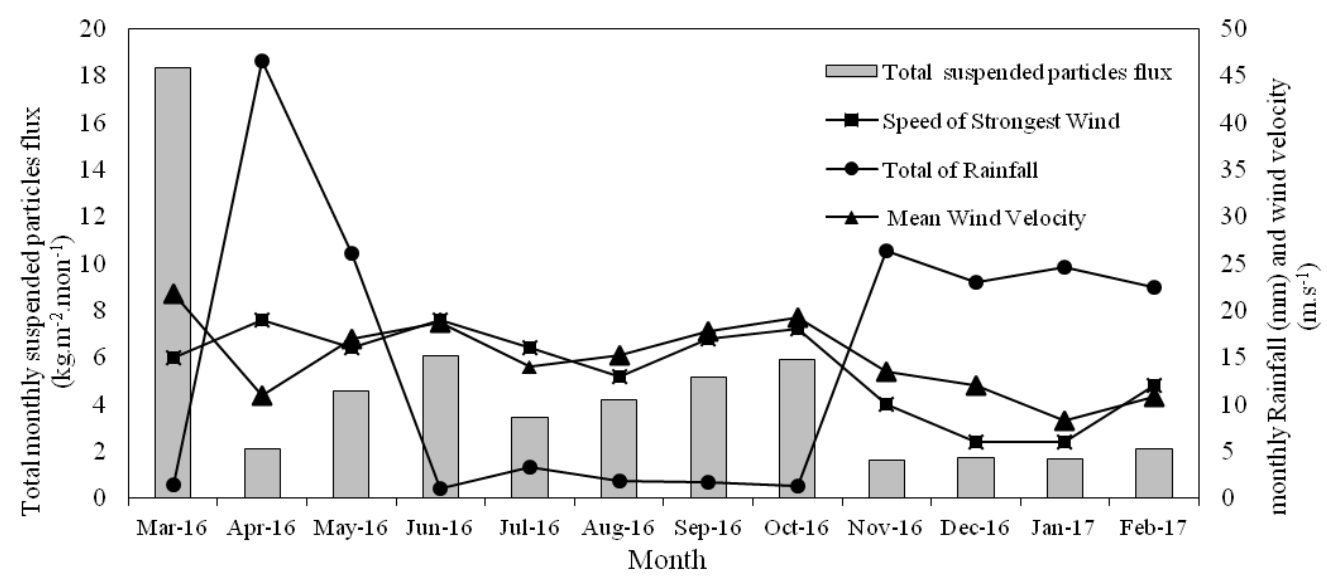

Figure 8. Variation of monthly suspended particles flux (grey bars) and its relationship with the main meteorological parameters at the studysite

Table 5. Correlation coefficients between monthly suspended particles flux and main meteorological parameters during research period

\begin{tabular}{c|c|c|c|c}
\hline & F & MW & SW & P \\
\hline F & 1 & $0.609^{*}$ & $0.516^{\mathrm{ns}}$ & $-0.779^{* *}$ \\
MW & & 1 & $0.818^{* *}$ & $-0.698^{*}$ \\
SW & & & 1 & $-0.509^{\mathrm{ns}}$ \\
P & & & & 1 \\
\hline
\end{tabular}

$\mathrm{ns},{ }^{*}$ and ${ }^{* *}$ are insignificant, significant at $\mathrm{P} \leq 0.05$ and $\mathrm{P} \leq 0.01$

Aeolian transport mainly occurs in March, June, and October in the Lake Urmia area. These months account for 53\% of the total annual suspended particles flux (Fig. 9). March has the greatest Aeolian transport. 
The comparison between suspended particles flux and the average 11 years of meteorological data (from 2000 until 2011) at the studied area (Fig. 10 and Table 6) shows that there is a correlation between the monthly precipitation and monthly suspended particles flux, too.

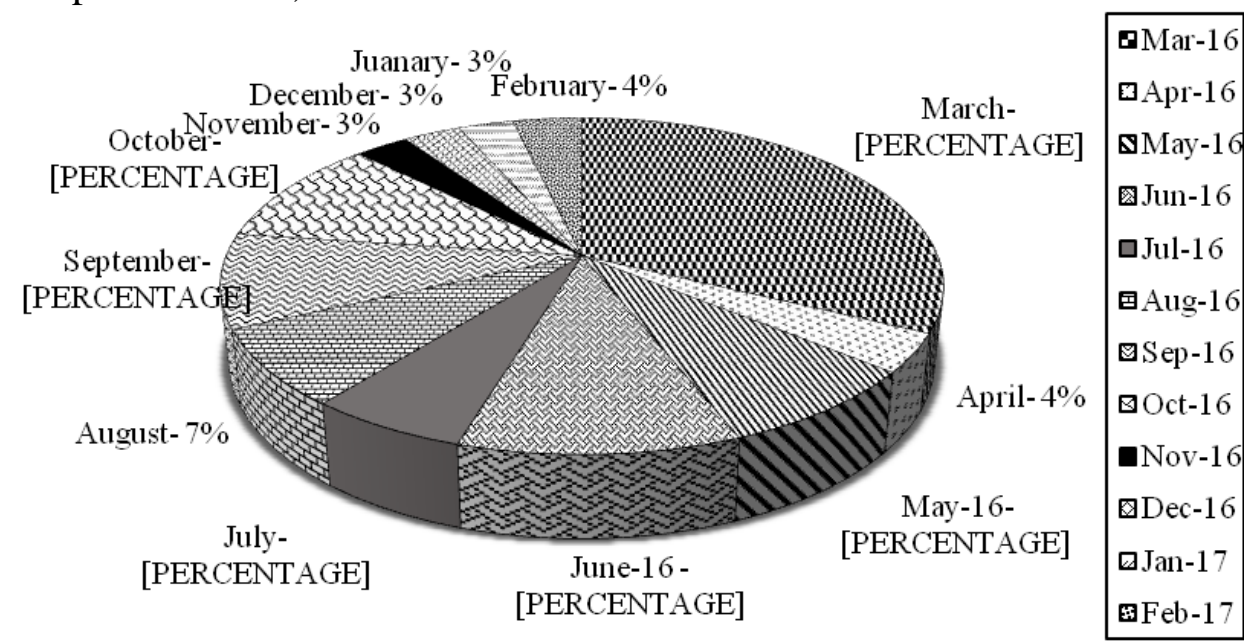

Figure 9. Share of each month of the total annual suspended particles flux

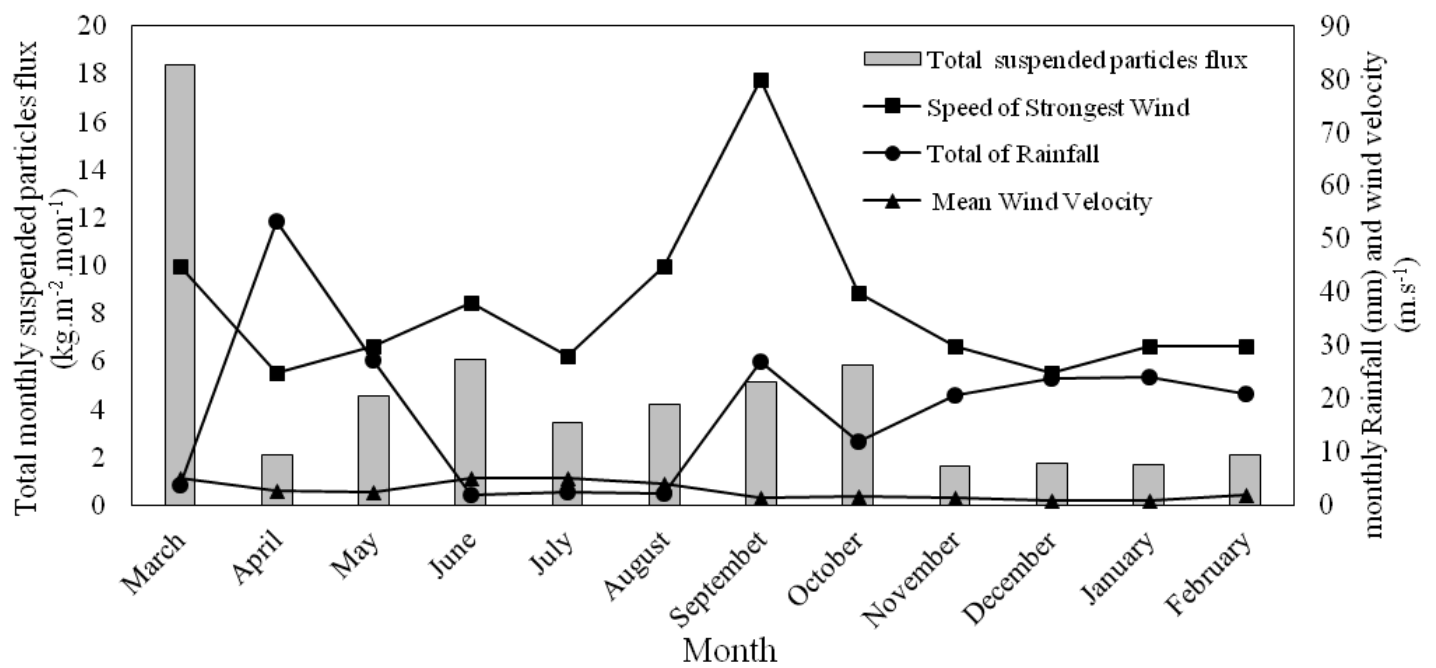

Figure 10. Variation of monthly suspended particles flux (grey bars) and its relationship with the average 11 years of meteorological data (from 2000 until 2011) in the studied area

Table 6. Correlation coefficients between monthly suspended particles flux and the average 11 years of meteorological data (from 2000 until 2011)

\begin{tabular}{c|c|c|c|c}
\hline & F & MW & SW & P \\
\hline F & 1 & $0.581^{*}$ & $0.349^{\mathrm{ns}}$ & $-0.608^{*}$ \\
MW & & 1 & $0.024^{\mathrm{ns}}$ & $-0.44^{\mathrm{ns}}$ \\
SW & & & 1 & $-0.153^{\mathrm{ns}}$ \\
P & & & & 1 \\
\hline
\end{tabular}

$\mathrm{ns},{ }^{*}$ and ${ }^{* *}$ are insignificant, significant at $\mathrm{P} \leq 0.05$ and $\mathrm{P} \leq 0.01$ 


\section{The effects of height of soil surface, sampling time and sampling site on the suspended particle's flux}

To study the effects of sampling time during research period (from March 2016 until February 2017) and height of soil surfaces $(0.15,0.5,1$ and $2 \mathrm{~m})$ on suspended particles flux, the data of suspended particles flux in different times and heights were analyzed. The results of variance analysis (mean and corresponding effects) (Table 7) showed that corresponding effect of sampling time and height of soil surface on suspended particles flux were significant $(\mathrm{P} \leq 0.01)$.

Table 7. Mean squares of sampling time and height of soil surface effects on suspended particles flux

\begin{tabular}{c|c|c}
\hline Source & Df & Mean squares \\
\hline The height of soil surface & 3 & $0.265^{* *}$ \\
Sampling time & 11 & $0.377^{* *}$ \\
Height of soil surface $\times$ sampling time & 33 & $0.035^{* *}$ \\
Error & 624 & 0.007 \\
\hline CV\% & & 45.42 \\
\hline
\end{tabular}

ns, ${ }^{*}$ and ${ }^{* *}$ are insignificant, significant at $\mathrm{P} \leq 0.05$ and $\mathrm{P} \leq 0.01$

The mean comparison results of the corresponding effect of sampling time and height of soil surface on suspended particles flux (Fig. 11) showed that when the height of soil surface increased, the suspended particles flux decreased. This was accordance with results of Dong et al. (2010) and Zobeck and Fryrear (1986) studies.

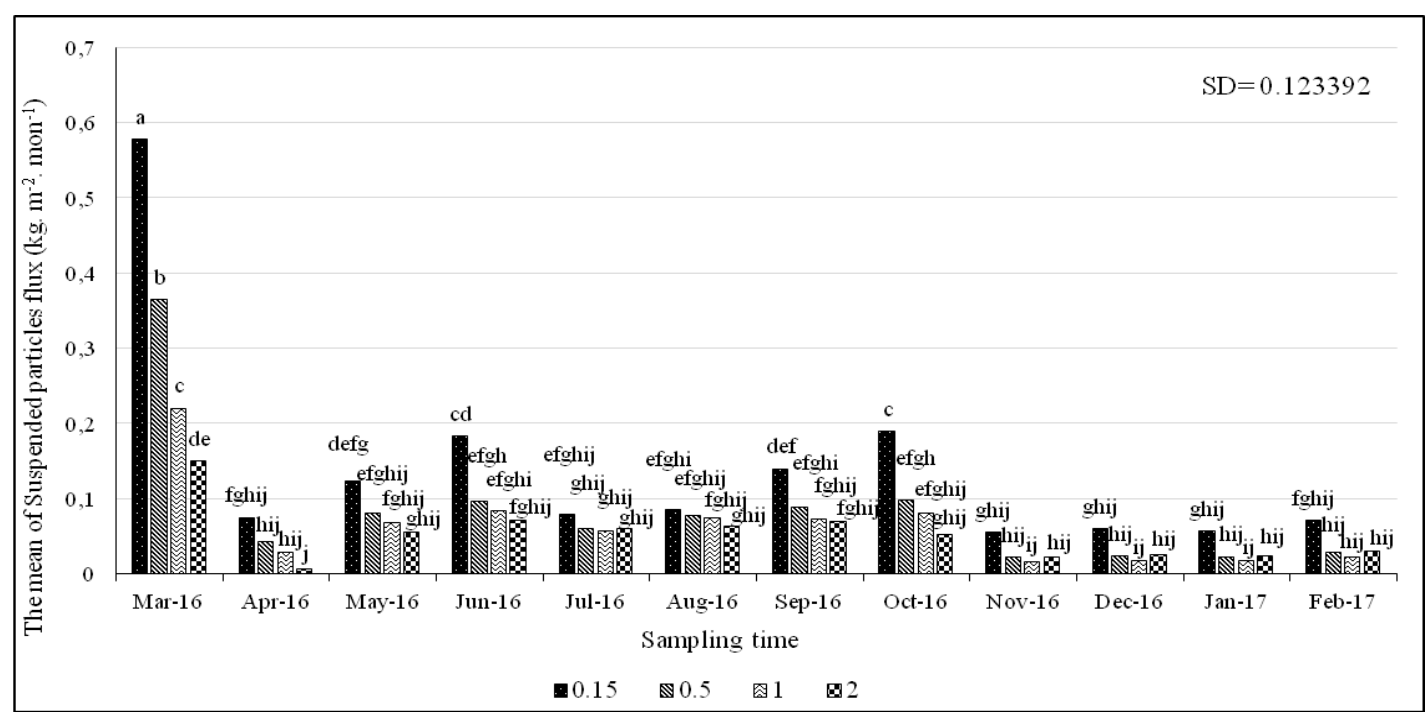

Figure 11. Mean comparison of the corresponding effect of sampling time and sampling height of soil surface on suspended particles flux

To study the effects of sampling time during research period (from March 2016 until February 2017) and sampling site (sampler's distance from each other by 14 poles that were installed in different sites) on suspended particles flux, data of calculated flux in 
different times and sites were analyzed. The results of variance analysis (Table 8) showed that the mean effects of sampling time and sampling site on suspended particles flux were significant $(\mathrm{P} \leq 0.01)$, but the corresponding effect of sampling time and sampling site was insignificant.

Table 8. Mean squares of sampling time and sampling site effects on suspended particles flux

\begin{tabular}{c|c|c}
\hline Source & df & Mean squares \\
\hline Sampling time & 11 & $0.378^{* *}$ \\
Sampling site & 13 & $0.019^{* *}$ \\
Sampling site $\times$ sampling time & 143 & $0.01^{\text {ns }}$ \\
Error & 504 & 0.009 \\
\hline CV\% & & 45.65 \\
\hline
\end{tabular}

$\mathrm{ns},{ }^{*}$ and ${ }^{* *}$ are insignificant, significant at $\mathrm{P} \leq 0.05$ and $\mathrm{P} \leq 0.01$

The mean comparison result of the main effect of sampling time on suspended particles flux (Fig. 12) showed that there was a significant difference $(\mathrm{P} \leq 0.01)$ between different times of sampling. The greatest mean of suspended particles flux was in March 2016. According to (Fig. 8), the amount of precipitation was low and wind velocity was high in this month. Actually, there was an inverse correlation between suspended particles flux and total monthly rainfall.

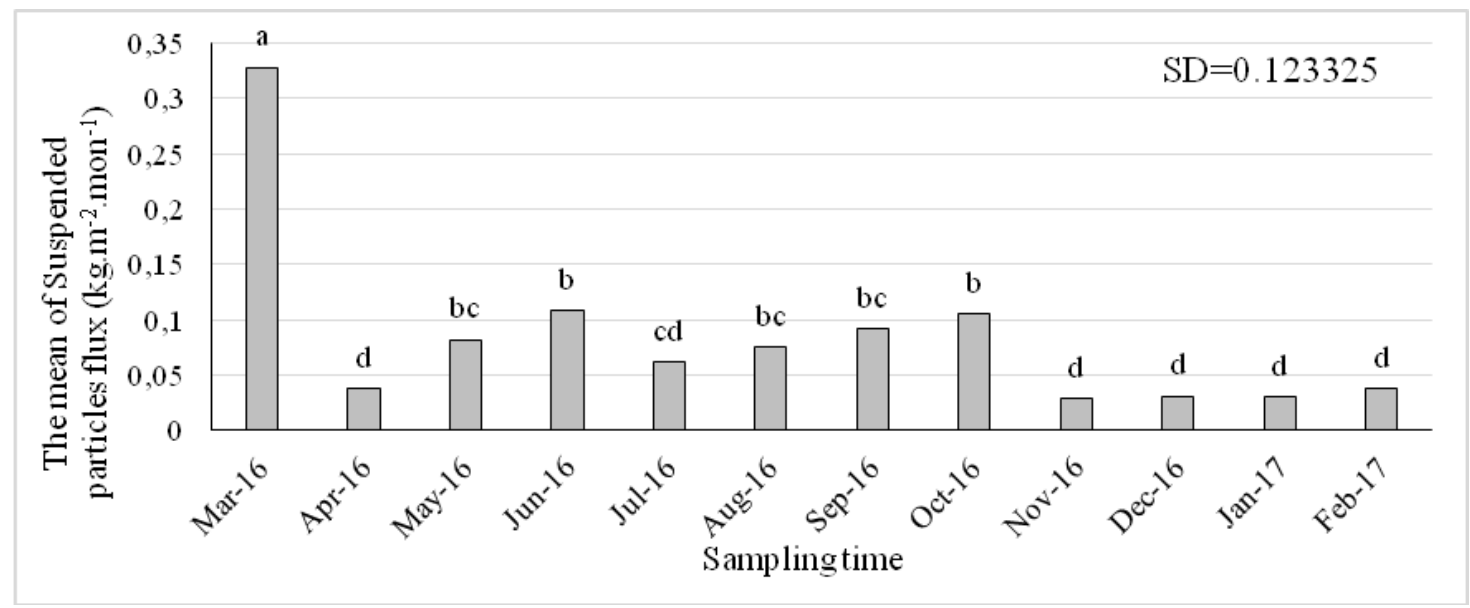

Figure12. Mean comparison of the main effect of sampling time on suspended particles flux

The mean comparison result of the main effect of sampling site on suspended particles flux (Fig. 13) showed that there was significant difference $(\mathrm{P} \leq 0.01)$ between different sampling sites, but just in one site (I-pole), differences were significant compared to other sites, and it was ignored, suggesting that the sampling site did not influence flux. Therefore, the 14 poles were installed in a circular pattern in different directions (Fig. 4). This can be inferred as the wind direction did not influence on suspended particles flux. 


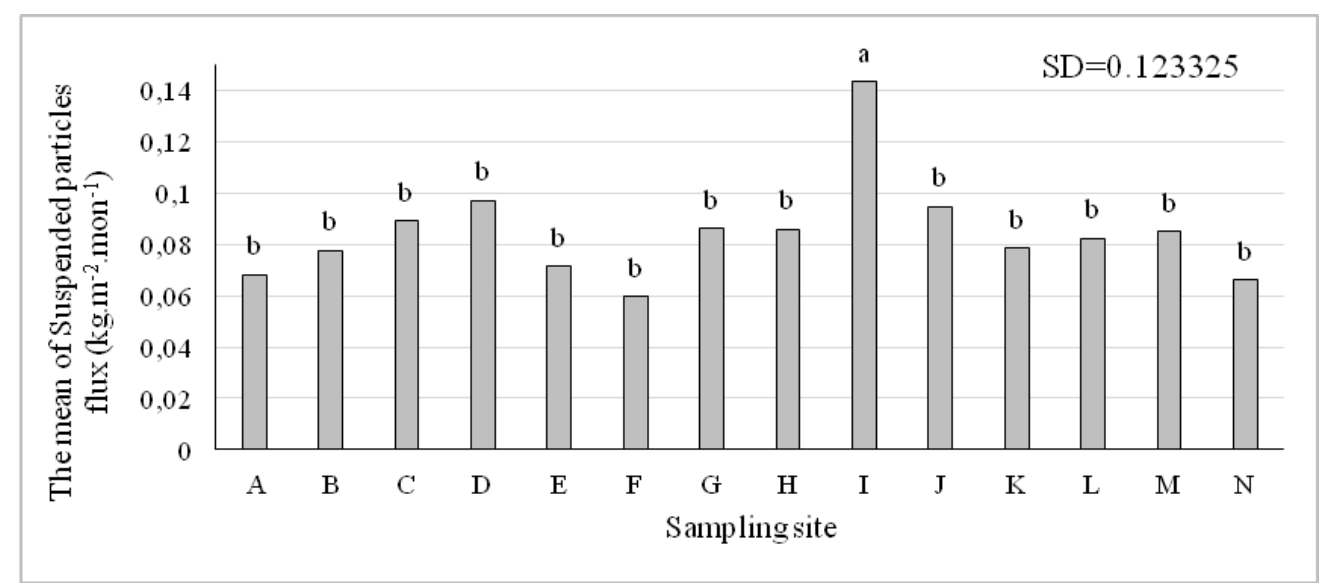

Figure13. Mean comparison of the main effect of sampling site on suspended particles flux

\section{Conclusions}

In this research study, we measured the horizontal flux of suspended particles for the one-year duration in surrounding dry lands of lake Urmia which is one of the main aeolian dust deposit in N.W.of Iran. The results of our study showed that the strongest aeolian transport dust occurs in March, June, and October. These months had the lowest amount of precipitation.

The horizontal suspended particles flux showed that it had a strong correlation with the amount of monthly precipitation and monthly mean wind velocity but there was no significant relationship between monthly suspended particles flux and speed of the strongest wind during the time of the study. The result also showed that the wind direction did not influence on suspended particles flux. Hence, due to a shortage of rainfall and the lack of soil surface covering in March, the amount of suspended particles flux was greatest in this month. Parameters such as different hight of the soil surface, different sampling times and different sampling sites had a significant effect $(\mathrm{P} \leq 0.01)$ on suspended particles flux.

Several authors have proposed a power decay law to describe the variation in suspended flux with height, and we used that approach to provide a good fit for the observed data in this study.

Finally, our finding showed that the majority of suspended flux transported below $1 \mathrm{~m}$ height of soil surface will settle back to the ground in a short distance. This finding can help us in implementing the prevention programs such as windbreaker building. The design of the height and distance of windbreakers are important for their efficiency usage.

To confront wind erosion by mechanical means, the windbreaker is one of the direct methods of prevention. Other mechanical methods are mulching and plowing the land in opposite direction of the dominant slope. Indirect methods are planting the native plant vegetation that grows in the region. Usually, these are the halophytic vegetation. Protecting grassland from degradation and rehabilitating the dried-up terminal lake will be important steps in reducing and preventing future dust storm.

For future studies, we suggest that the suspended particles flux be examined as toxin materials in surrounding lake Urmia area. We recommend that trace toxic elements and other elements such as $\mathrm{Na}, \mathrm{Ca}, \mathrm{K}, \mathrm{Mg}, \mathrm{Al}$ and heavy metals such as $\mathrm{Fe}, \mathrm{Mn}, \mathrm{Si}$ be measured for purpose of health considerations, because the area is designated as one of the locations that are susceptible to hazards of dust pollution. 


\section{REFERENCES}

[1] Asghai Zamani, A. (2013): Evaluation of Urmia lake level changes as profound environmental challenges facing the North West of Iran. - Geographic Space 13(41): 7791.

[2] Dong, Z., Man, D., Luo, W., Qian, G., Wang, J., Zhao, M., Liu, S., Zhu, G., Zhu, S. (2010): Horizontal aeolian sediment flux in the Minqin area, a major source of Chinese dust storms. - Geomorphology 116: 58-66.

[3] FAO (Food and Agriculture Organization of the United Nations) (2015): Status of the World's Soil Resources, Main Report - Chapter6 - Global Soil Status, Processes, and Trends. - Food and Agriculture Organization of the United Nations and Intergovernmental Technical Panel on Soils, Rome.

[4] Fryrear, D. W. (1986): A field dust sampler. - Journal of Soil and Water Conservation 41(2): 117-120.

[5] Fryrear, D. W. (1987): Aerosol Measurements from 31 Dust Storm. - In: Ariman, T., Veziroglu, T. N. (eds.) Particulate and Multiphase Proceeding, 2. Contamination Analysis and Control. Hemisphere Publishing Corporation, New York.

[6] Fryrear, D. W., Stout, J. E., Gillette, D. A. (1988): Instrumentation for wind erosion. Proc. Wind Erosion Conference, Lubbock, TX.

[7] Fryrear, D. W., Saleh, A. (1993): Field wind erosion: vertical distribution. - Soil Science 155(4): 294-300.

[8] Fryrear, D. W., Stout, J. E., Hagen, L. J., Vories, E. D. (1991): Wind erosion: Field measurement and analysis. - American Society of Agricultural Engineers 34(1): 155-160.

[9] Goossens, D., Buck, B. J. (2012): Can BSNE (Big Spring Number Eight) samplers be used to measure PM10, respirable dust, PM2.5, and PM1.0. - Aeolian Research 5: 43-49.

[10] Goossens, D., Offer, Z. Y. (2000): Wind tunnel and field calibration of six Aeolian dust samplers. - Atmospheric Environment 34: 1043-1057.

[11] Shannak, B., Corsmeier, U., Kottmeier, C., Al-azab, T. (2014): Wind tunnel study of twelve dust samples with large particle size. - Atmospheric Environment 98: 442-453.

[12] Tajrishi, M. M. (2016): The revival of Urmia Lake, Challenges, and necessities. - The International Conference on Geographic and Environmental Impacts of Urmia Lake Conditions, The University of Tabriz, Iran, November.

[13] Vories, E. D., Fryrear, D. W. (1988): Field measurements of wind erosion. - 1988 Wind Erosion Conference Proceedings, Lubbock, Texas.

[14] Wang, G., Wanquan, T., Mingyuan, D. (2004): Flux and composition of wind-eroded dust from different landscapes of an arid inland river basin in north-western China. Journal of Arid Environments 58: 373-385.

[15] Zobeck, T. M., Fryrear, D. W. (1986): Chemical and Physical Characteristics of windblown sediments. I. Quantities and Physical Characteristics. - American Society of Agricultural Engineers 29(4): 1032-1036. 